\title{
Perancangan Alat Laju Penguapan (Evaporasi) Air Garam dengan pendekatan Bodyspace Orang Madura
}

\author{
Rullie Annisa ${ }^{\left.{ }^{*}\right)}$, Hanifudin Sukri ${ }^{2 *}$ Hairil Budiarto ${ }^{3)}$ Rohmat Khaironi ${ }^{4)}$ R Daksena Abdi Putera \\ ,) Teknik Industri, Fakultas Teknik, Universitas Trunojoyo \\ 2) Teknik Elektro, Fakultas Teknik, Universitas Trunojoyo \\ ${ }^{3)}$ Teknik Mekatronika, Fakultas Teknik, Universitas Trunojoyo \\ rullie.annisa@trunojoyo.ac.id ${ }^{\left.{ }^{*}\right)}$ hanifudinsukri@trunojoyo.ac.id ${ }^{2)}$ haidar_060282@trunojoyo.ac.id ${ }^{3)}$ \\ rohmatkhaironi@gmail.com ${ }^{4)}$ senaputra1998@gmail.com ${ }^{5)}$
}

DOI: https://doi.org/10.21107/rekayasa.v12i2.5923

\begin{abstract}
Abstrak
Perancangan alat laju penguapan (evaporasi) air garam perlu memperhatikan aspek ergonomic guna kesesuaian alat dengan petani tambak sebagai pengguna. Salah satu pendekatan ergonomic yang digunakan dalam perancangan alat laju penguapan air garam yaitu metode bodyspace. Tujuan penelitian ini adalah agar perancangan alat laju penguapan sesuai dengan antropometri orang Madura berjenis kelamin pria selaku pengguna. Berdasarkan data antropometri orang Madura berjenis kelamin pria pada rentang usia 21-24 tahun, data dimensi tubuh yang digunakan terkait pendekatan bodyspace yaitu data D1,D2,D4,D24,D25,D28,D29,D33 dan D34, dengan persentil sebesar 95\%. Hasil penelitian menunjukkan dengan memperhatikan data dimensi pada D1,D2 dan D34 ketinggian alat minimum sebesar $123 \mathrm{~cm}$ tinggi maksimum sebesar $193 \mathrm{~cm}$, data D33 panjang alat sebesar $56 \mathrm{~cm}$, data D24 dan D25 lebar alat sebesar 54 $\mathrm{cm}$, data D2 ketinggian LCD sebesar $81 \mathrm{~cm}$, data D28,D29 panjang handle sebesar $11 \mathrm{~cm}$, data D28,D29 dan D33 ukuran wadah diperoleh panjang $30 \mathrm{~cm}$, lebar $30 \mathrm{~cm}$ dan tinggi $9 \mathrm{~cm}$. Berdasarkan hasil yang diperoleh, maka diketahui bahwa perancangan alat laju penguapan perlu dibuat secara fleksibel sesuai dengan data dimensi Antropometri orang Madura sebagai penggunanya.
\end{abstract}

Kata kunci : Perancangan, alat laju penguapan air garam, ergonomic, antropometri, bodyspace, workspace

\section{Abstract}

\section{Design of Salt Water Evaporation Tools using the Madurese Bodyspace}

The design of the evaporation rate for salt water needs to pay attention to ergonomic aspects for the suitability of the tool with the farmer farmer as the user. One ergonomic approach used in the design of the salt water evaporation rate tool is the bodyspace method. The purpose of this study is that the design of the evaporation rate tool is in accordance with the anthropometry of male Madurese as the user. Based on anthropometric data of male Madurese in the age range of 21-24 years, body dimension data used is related to the bodyspace approach namely data D1, D2, D4,, D24, D25, D28, D29, D33 and D34, with 95\% percentile. The results showed by taking into account the dimension data on D1, D2 and D34 the minimum height of the tool is $123 \mathrm{~cm}$, the maximum height is $193 \mathrm{~cm}$, the D33 data is $56 \mathrm{~cm}$, the D24 and D25 data is $54 \mathrm{~cm}$, the D2 height is $81 \mathrm{~cm}$, data D28, D29 handle length of $11 \mathrm{~cm}$, data D28, D29 and D33 container size obtained length $30 \mathrm{~cm}$, width $30 \mathrm{~cm}$ and height $9 \mathrm{~cm}$. Based on the results obtained, it is known that the design of the evaporation rate tool needs to be made flexibly according to the Madurese Anthropometric dimension data as its user. Keywords: Design, salt water evaporation rate tool, ergonomics, anthropometry, bodyspace, workspace

\section{PENDAHULUAN}

Pulau Madura merupakan pamasok utama garam di tanah air, sehingga pulau Madura disebut sebagai Pulau Garam. Luas lahan garam di Madura mencapai 15.000 hektare. Semua kabupaten yang terdapat di Pulau Madura, yaitu Bangkalan, Sampang, Pamekasan dan Sumenep memiliki tambak garam yang luas. Selain daerah-daerah tersebut juga produktif karena dapat menghasilkan garam dalam jumlah besar (Kementerian Pariwisata, 2019). Produksi garam di Madura ternyata juga

\section{Article History:}

Received: August, 30th 2019; Accepted: September, $29^{\text {th }} 2019$ ISSN: 2502-5325 (Online) Terakreditasi Peringkat 3 oleh Kementerian Riset, Teknologi dan Pendidikan Tinggi (ARJUNA), berdasarkan Keputusan Direktur Jenderal Penguatan Riset dan Pengembangan No: 23/E/KPT/2019 tanggal 8 Agustus 2019 didukung oleh letak geografis Pulau Madura. Musim kemarau yang lebih panjang, sekitar 4 hingga 5 bulan. Ditambah bulan kering yang dapat berlangsung selama 2 hingga 4 bulan. Kondisi ini sangat cocok untuk proses pembentukan garam air laut yang membutuhkan panas matahari dan angin dari pantai (Kementerian Pariwisata, 2019).

Proses pembentukan garam dari air laut merupakan salah satu proses dari evaporasi yang dibantu oleh penyinaran matahari. Penguapan atau evaporasi adalah proses perubahan molekul di da-

\section{Cite this as:}

Annisa, R. Sukri, H. Budiarto, H. Khaironi, R. \& Putera, R.D.A. (2019). Perancangan Alat Laju Penguapan (Evaporasi) Air Garam dengan pendekatan Bodyspace Orang Madura. Rekayasa, 12(2), 151-156. doi:https://doi.org/10.21107/rekayasa.v12i2.5923 (c) 2019 Rullie Annisa, Hanifudin Sukri, Hairil Budiarto, Rohmat Khaironi, R Daksena Abdi Putera 
lam keadaan cair (contohnya air) dengan spontan menjadi gas (contohnya uap air). Sisa penguapan pada larutan yang mengandung mineral tertentu ini akan menjadi Kristal-kristal garam mineral (Aris, 2011). Salah satu cara untuk mengontrol factor laju penguapan air garam yaitu dengan merancang Alat laju penguapan (evaporasi) air garam dengan memperhatikan desain alat yang ergonomic sesuai dengan antropometri dengan pendekatan bodyspace.

Perbedaan populasi dan suku berpotensi menimbulkan adanya perbedaan antropometri, meskipun berasal dari satu negara (Abeysekera dan Shahnavaz, 1989). Database antropometri di Indonesia dianggap sebagai faktor penting dan menjadi pertimbangan perancangan peralatan, seperti untuk modernisasi peralatan pertanian di Indonesia (Wibowo dan Soni, 2014). Kesesuaian data antropometri dengan perancangan peralatan sangat diperlukan untuk pengoptimalan kinerja peralatan dan menghindari cidera atau kecelakaan pada pengguna, sehingga perlu adanya data antropometri yang terstruktur (Chuan dkk, 2010).

Berdasarkan hal tersebut maka perancangan alat laju penguapan (evaporasi) air garam dibuat sesuai dengan anthropometri bodyspace orang Madura berjenis kelamin pria dewasa selaku petani tambak garam umumnya. Hal ini bertujuan agar alat yang dirancang dapat dimanfaatkan secara optimal oleh petani tambak Madura, sehingga terdapat kesesuaian antara alat dan pengunanya.

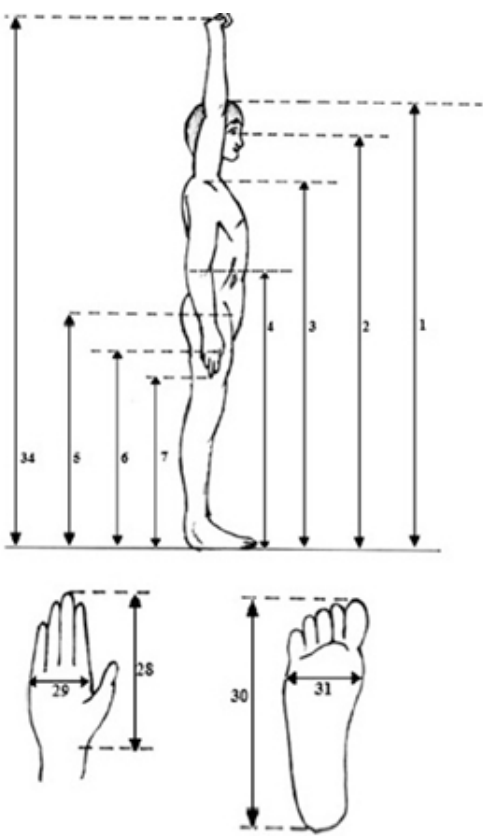

\section{METODE PENELITIAN}

Penelitian ini dimulai pada minggu ke dua bulan Juli hingga ketiga bulan Agustus 2019 bertempat di laboratorium ergonomi dan perancangan system kerja dan laboratorium mekatronika. Perancangan Alat Laju Penguapan (evaporasi) air garam memperhatikan factor ergonomic yaitu antropometri dengan pendekatan bodyspace. Kroemer dan Grandjean (2005) mendefinsikan antropometri sebagai ilmu pengukuran dimensi tubuh dan menjadi suatu faktor penting dalam mempertimbangkan proses perancangan fasilitas atau peralatan, karena antropometri digunakan sebagai penyesuaian tugas dengan manusia. Penggunaan antropometri untuk perancangan alat, peralatan, maupun lingkungan kerja yang dirancang dengan baik sehingga dapat meningkatkan produktivitas, keselamatan, kenyamanan, keamanan dan peningkatan kinerja kerja dalam beraktivitas (Klamklay $\mathrm{dkk}, 2008)$

Perkembangan database antropometri Indonesia dipengaruhi oleh persamaan dan perbedaan ukuran antropometri antar suku di Indonesia berdasarkan suku, namun hanya digunakan sebagai studi antropometri mengenai perbedaan suku di Indonesia (Chuan dkk, 2010). Pada penelitian Wibowo dan Soni (2014) didapatkan antropometri untuk alat kerja tangan masyarakat suku Jawa dan suku Madura yang tinggal pada kabupaten Jember, Lumajang dan Banyuwangi bahwa beberapa dimensi tubuh Masyarakat suku Jawa lebih besar dari pada suku Madura. Database antropometri bodyspace dalam pebuatan alat laju penguapan (evaporasi) air garam dikutip dari penelitian Fikri

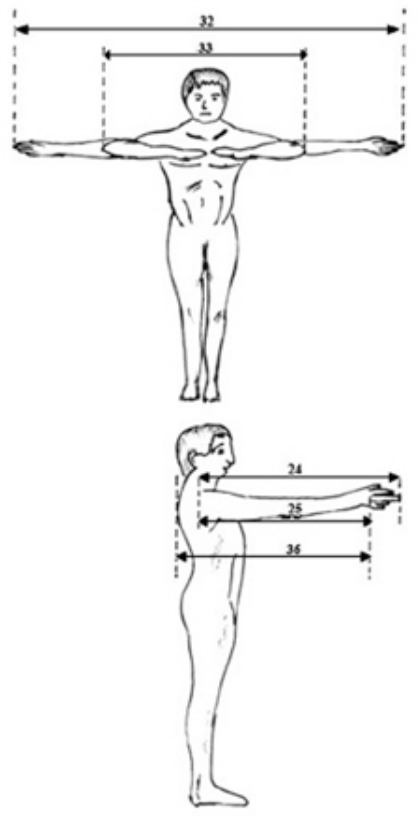

Gambar 1. Bodyspace posisi berdiri 
Tabel 1. Data bodyspace alat laju penguapan (evaporasi) air garam

\begin{tabular}{|c|c|c|c|}
\hline No. & $\begin{array}{c}\text { Notasi } \\
\text { Dimensi }\end{array}$ & Dimensi & Definisi \\
\hline 1 & D1 & Tinggi Tubuh & Jarak vertikal dari lantai ke bagian paling atas kepala \\
\hline 2 & D2 & Tinggi Mata & Jarak vertikal dari lantai ke bagian luar sudut mata kanan \\
\hline 3 & D3 & Tinggi Bahu & $\begin{array}{l}\text { Jarak vertikal dari lantai kebagian atas bahu kanan (acromion atau } \\
\text { ujung tulang bahu kanan }\end{array}$ \\
\hline 4 & D4 & Tinggi Siku & Jarak vertikal dari lantai ke titik terbawah di sudut suku bagian kanan \\
\hline 5 & D24 & Panjang Rentang Tangan & $\begin{array}{l}\text { Jarak dari bagian atas bahu kanan (acromion)ke ujung jari tengah } \\
\text { tangan kanan dengan siku dan pergelangan tangan kanan lurus }\end{array}$ \\
\hline 6 & D25 & $\begin{array}{l}\text { Panjang Bahu Genggaman } \\
\text { Tangan ke Depan }\end{array}$ & $\begin{array}{l}\text { Jarak dari bagian atas bahu kanan (acromion) ke pusat batang silinder } \\
\text { yang digenggam oleh tangan kanan, dengan siku dan pergelangan } \\
\text { tangan lurus }\end{array}$ \\
\hline 7 & D28 & Panjang Tangan & $\begin{array}{l}\text { Jarak dari lipatan pergelangan tangan ke ujung jari tengah kanan } \\
\text { pada pososi tangan dan seluruh jari lurus dan terbuka }\end{array}$ \\
\hline 8 & D29 & Leher Tangan & $\begin{array}{l}\text { Jarak antara kedua sisi luar empat buku jari tangan kanan yang } \\
\text { diposisikan lurus dan rapat }\end{array}$ \\
\hline 9 & D33 & Panjang Rentang Siku & $\begin{array}{l}\text { Jarak yang diukur dari ujung siku tangan kanan ke ujung siku tangan } \\
\text { kiri }\end{array}$ \\
\hline 10 & D34 & $\begin{array}{l}\text { Tinggi Genggaman ke atas } \\
\text { dalam posisi berdiri }\end{array}$ & $\begin{array}{l}\text { Jarak vertikal dari lantai ke pusat batang silinder (center of a } \\
\text { cylendrical rod) yang digenggam oleh telapak tangan kanan }\end{array}$ \\
\hline
\end{tabular}

(2017) tentang database antropometri bodyspace masyarakat dewasa muda suku Madura dengan 36 data antropometri bodyspace.

Dari 36 data antropometri bodyspace pada penelitian Fikri (2017) hanya 10 data bodyspace yang digunakan pada perancangan alat laju penguapan (evaporasi) air garam yaitu bodyspace pada posisi berdiri, dirangkum pada tabel 1 .

\section{HASIL DAN PEMBAHASAN}

Masyarakat madura memiliki ketinggian tubuh rata-rata yaitu antara $160 \mathrm{~cm}$ hingga $170 \mathrm{~cm}$, masyarakat pria suku Madura memiliki wajah lebih lebar dan tidak halus, tulang pipinya menonjol keluar dan keliahatan kasar, jika dibandingkan dengan masyarakat pria suku Jawa, masyarakat pria suku Madura memiliki postur tubuh lebih tegap dan berotot meskipun lebih pendek dari pada masyarakat pria suku jawa (De Jonge, 1995). Perancangan alat laju penguapan air garam dirancang khusus untuk petani garam di wilayah Madura. Perancangan yang tidak sesuai dapat menurunkan produktivitas dari nilai guna suatu alat atau fasilitas yang dirancang, salah satu penyebabnya yaitu ketidaksesuaian antara rancangan dengan keterbatasan data antropometri yang ada, sehingga racangan yang dibuat hanya berdasarkan pada ukuran rancangan yang telah ada (Purnomo, 2014). Berdasarkan hal tersebut, data antropometri bodyspace yang digunakan yaitu antropometri dewasa muda masyarakat Madura (Fikri, 2017). Adapun data persentil yang ditentukan untuk mengetahui patokan ukuran perancangan desain alat laju penguapan (evaporasi) air garam sehingga tidak melebihi ukuran antropometri masyarakat Madura (Fikri, 2017) pada tabel 2.

Perancangan alat laju penguapan air garam berdasarkan dimensi yang telah ditentukan dilakukan untuk memudahkan pengguna dalam menggunakan alat laju penguapan air garam dengan nyaman dan fleksibel, sehingga di desain dengan konsep tinggi maksimal dan tinggi minimal. Alat laju penguapan air garam terdiri dari beberapa bagian, yaitu meja, wadah air garam dan sensor-sensor yang akan digunakan untuk mengukur variabel agar dapat menentukan titik kelayakan wilayah tambak garam, sebagaimana pada gambar 2, gambar 3 dan gambar 4 .

Tabel 2. Data bodyspace alat laju penguapan (evaporasi) air garam

\begin{tabular}{ccccc}
\hline Dimensi & Rata-Rata & SD & \multicolumn{2}{c}{ Persentil } \\
& & & 5 & 95 \\
\hline D1 & 165.00 & 4.00 & 158.45 & 171.55 \\
D2 & 155.70 & 4.73 & 147.94 & 163.46 \\
D3 & 138.10 & 3.42 & 132.49 & 143.71 \\
D4 & 103.80 & 1.15 & 101.92 & 105.68 \\
D24 & 74.91 & 1.04 & 73.2 & 76.62 \\
D25 & 65.96 & 1.08 & 64.18 & 67.74 \\
D28 & 17.24 & 0.80 & 15.92 & 18.56 \\
D29 & 8.54 & 0.61 & 7.54 & 9.55 \\
D33 & 98.64 & 3.30 & 93.22 & 106.06 \\
D34 & 192.04 & 4.39 & 184.84 & 199.24 \\
\hline
\end{tabular}



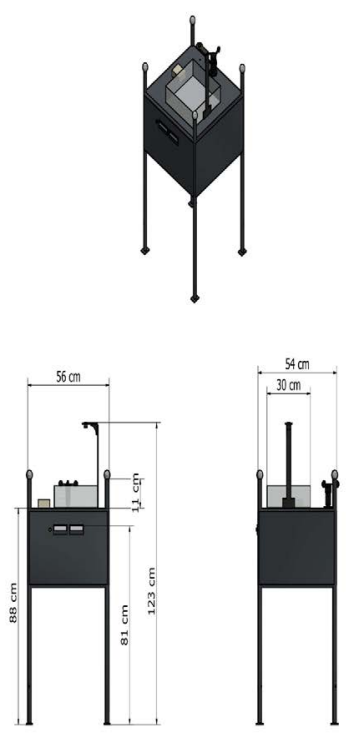

Gambar 2. Rancangan Alat laju penguapan air garam posisi tinggi minimal

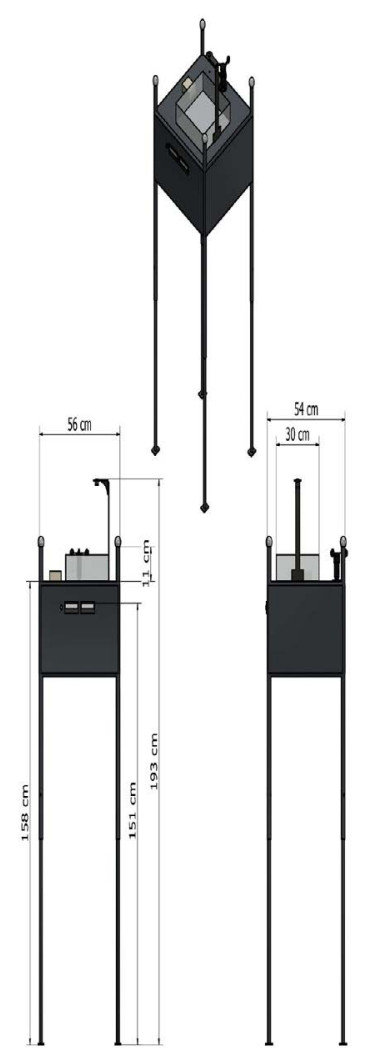

Gambar 3. Rancangan Alat laju penguapan air garam posisi tinggi maksimal

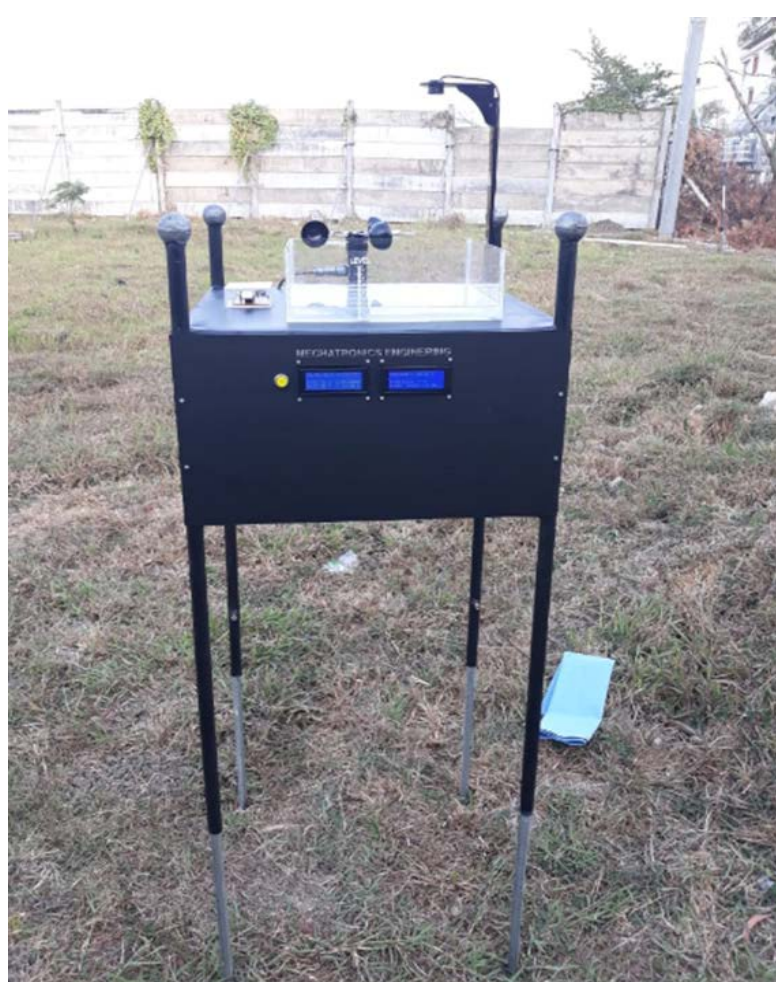

Gambar 4. Alat laju penguapan air garam

Alat laju penguapan air garam memiliki ketinggian minimum sebesar $123 \mathrm{~cm}$. Hal tersebut didasarkan pada dimensi D1 atau dimensi tinggi tubuh sebesar $171 \mathrm{~cm}$, dimensi D2 atau dimensi tinggi mata memiliki ketinggian $163 \mathrm{~cm}$ dan D34 atau tinggi genggaman tangan ke atas dalam posisi berdiri sebesar $199 \mathrm{~cm}$ sehingga akan memudahkan pengguna dalam melihat segala perankat yang terdapat di atas meja, melihat indikator water level pada wadah air garam yang terletak diatas meja bahkan memudahkan pengguna dalam melakukan setting pada alat atau sensor cahaya. Tambak garam terkadang memiliki topografi tanah yang tidak menentu bahkan tidak rata yang berakibat pada alat akan mengalami kemiringan sehingga alat tidak optimal dalam melakukan fungsi dan kegunaannya. Mengantisipasi hal tersebut maka alat laju penguapan air garam diberi fitur fleksibelitas yaitu bagian kaki dapat ditambah ketinggiannya. Bagian kaki dapat ditambah ketinggiannya hingga $70 \mathrm{~cm}$ sehingga total ketinggian maksimum mencapai $193 \mathrm{~cm}$. Fungsi sekunder dari fitur fleksibelitas yaitu dapat digunakan untuk menyesuaikan jarak pandang antara pengguna dengan alat berdasarkan dimensi tubuh pengguna.

Alat laju penguapan air garam memiliki dimensi panjang sebesar $56 \mathrm{~cm}$. Hal ini dikarenakan dimensi D33 atau dimensi panjang rentang siku sebesar $106 \mathrm{~cm}$. Dimensi D33 sebesar $106 \mathrm{~cm}$ dapat memudahkan pengguna untuk menjangkau segala hal yang terdapat pada alat laju penguapan air garam seperti pengisian air garam, setting alat 
ukur atau sensor, memegang gagang atau handle untuk memindahkan alat laju penguapan air garam.

Alat laju air garam memiliki lebar sebesar $54 \mathrm{~cm}$. Hal tersebut didasarkan pada dimensi D24 atau dimensi panjang rentang tangan sebesar $76 \mathrm{~cm}$, dimensi D25 atau panjang bahu genggaman tangan ke depan sebesar $67,74 \mathrm{~cm}$. Dimensi tersebut dapat memudahkan pengguna untuk menjangkau segala hal yang terdapat pada alat laju penguapan air garam seperti pengisian air garam, setting alat ukur atau sensor, memegang gagang atau handle untuk memindahkan alat laju penguapan air garam.

Alat laju air garam memiliki ketinggian LCD sebesar $81 \mathrm{~cm}$ dalam keadaan ketinggian meja minimal namun ketinggian LCD dapat mencapai 151 $\mathrm{cm}$ dalam keadaan ketinggian meja maksimal. Hal ini dikarenakan dimensi D2 atau dimensi tinggi mata posisi berdiri sebesar $163 \mathrm{~cm}$ sehingga dapat memudahkan pengguna untuk melihat LCD tanpa harus mengangkat atau menundukan kepala dengan ekstrim yang berakibat pada keluhan pada bagian leher.

Proses memindahkan alat laju penguapan air garam dapat dilakukan dengan memegang bagian tinggi gagang atau handle dengan tinggi sebesar $11 \mathrm{~cm}$ atau memegang aksesoris berbentuk bola di bagian atas gagang yang memiliki dimensi diameter sebesar $4 \mathrm{~cm}$. Hal tersebut dikarenakan dimensi D28 atau dimensi panjang tangan sebesar $18 \mathrm{~cm}$ dan dimensi D29 atau dimensi leher tangan sebesar $9 \mathrm{~cm}$. Hal tersebut dapat memudahkan pengguna untuk memindahkan alat laju penguapan air garam dengan memegang bagian tinggi gagang atau handle maupun memegang aksesoris berbentuk bola di bagian atas gagang.

Ukuran wadah air garam yang terletak pada bagian atas meja alat memiliki dimensi panjang sebesar $30 \mathrm{~cm}$, lebar sebesar $30 \mathrm{~cm}$ dan tinggi sebesar $9 \mathrm{~cm}$ dengan ketebalan sebesar $1 \mathrm{~mm}$. Wadah tersebut terbuat dari material akrilik bening sehingga dapat memudahkan pengguna dalam melihat water level. Hal tersebut dikarenakan dimensi D33 atau dimensi panjang rentang siku sebesar $106 \mathrm{~cm}$, D28 atau panjang tangan sebesar $18 \mathrm{~cm}$ dan D29 atau leher tangan sebesar $9 \mathrm{~cm}$ sehingga dapat memudahkan pengguna untuk memegang hingga memindahkan wadah air garam.

\section{KESIMPULAN DAN SARAN}

Berdasarkan hasil yang diperoleh, maka diketahui bahwa perancangan alat laju penguapan perlu dibuat secara fleksibel sesuai dengan data dimensi Antropometri masyarakat dewasa muda Madura sebagai penggunanya, dengan memperhatikan data dimensi pada D1,D2 dan D34 ketinggian alat minimum sebesar $123 \mathrm{~cm}$ tinggi maksimum sebesar $193 \mathrm{~cm}$, data D33 panjang alat sebesar $56 \mathrm{~cm}$, data D24 dan D25 lebar alat sebesar $54 \mathrm{~cm}$, data D2 ketinggian LCD sebesar $81 \mathrm{~cm}$, data D28,D29 panjang handle sebesar $11 \mathrm{~cm}$, data D28,D29 dan D33 ukuran wadah diperoleh panjang $30 \mathrm{~cm}$, lebar $30 \mathrm{~cm}$ dan tinggi $9 \mathrm{~cm}$.

\section{DAFTAR PUSTAKA}

Abeysekera, J. D., Shahnavaz, H., 1989, Body Size Variability Between People in Developed and Developing Countries and Its Impact On The Use of Imported Goods, International Journal of Industrial Ergonomics.

Aris, Kabul. 2011. Pedoman Garam. Dirjen KP3K, Kementerian Kelautan dan Perikanan Republik Indonesia. Jakarta.

Bridger, R.S. 2003. Introduction to Ergonomics. Edisi ke-2. Taylor and Francis. New York-USA. ISBN 0-203-42613-4

Chuan, K. T., Hartono, M., dan Kumar, N., 2010, Anthropometry of The Singaporean and Indonesian Populations, International Journal of Industrial Ergonomics 40, 757-766.

De Jonge, Huub (ed.) 1995. Across Madura Strait. Leiden: KITLV Press.

Diakses pada 19 Maret 2018. Perhimpunan Ergonomi Indonesia. http://antropometriindonesia.org/

Fikri, A. 2018. Pengukuran Antropometri Mahasiswa Suku Madura. Bangkalan: Program Studi Teknik Industri, Fakultas Teknik, Universitas Trunojoyo Madura.

Hari, Purnomo. 2014. Pengukuran Antropometri Tangan Usia 18 Sampai 22 Tahun Kabupaten Sleman Yogyakarta..Prosiding Seminar Nasional IENACO - 2014 ISSN : 2337 - 4349.

https://pesona.travel/keajaiban/2850/menengok-pembuatan-garam-tradisional-di-madura

Jahanshahi, M., Golalipour, M.J., Heidari, K., 2008, The Effect of Ethnicity on Facial Anthropometry in Northern Iran, Singapore Med. J.,49, 940-943. 
156 | Annisa, R. dkk. Perancangan Alat Laju Penguapan (Evaporasi) Air Garam...

Klamklay, J., Sungkhapong, A., Yodpijit, N., Patterson, P.E., 2008. Anthropometry of the southern Thai population. International Journal of Industrial Ergonomics, 38, 111-118.

Kroemer, KHE, Grandjean E. 2005. Fitting the task to the human: A Textbook of Occupational Ergonomics. Edisi ke-5. Taylor \& Francis Publisher.

Nurmianto, E., 2003, Ergonomi Konsep Dasar dan Aplikasinya, Edisi Pertama, Guna Widya, Surabaya.

Peasant, S. (2014). Bodyspace: Anthropometry, ergonomics, and design. London: Taylor and Francis.

Pheasant, S. 2003. Bodyspace : Anthropometry, Ergonomics and Design of Work. Edisi ke-2. Taylor and Francis. ISBN 0-203-48265-4.

Sarjani. 2011. Cuaca dan Penguapan. Kumba. Jember.

Sukimi, Mohamad Fauzi . 2012. Cerita rakyat dan stereotaip dalam konteks pembinaan identiti Madura.
Syahadatin, N. (2012). Perancangan Ulang (Redesign) Tempat Tidur untuk Lansia dengan Metode Kansei Engineering dan Pendekatan Gerontology. Madura: Program Studi Teknik Industri, Fakultas Teknik, Universitas Trunojoyo Madura.

Wibowo, R. K. K. dan Soni, .P, 2014, Anthropometry and Agricultural Hand Tool Design for Javanese and Madurese Farmers in East Java, Indonesia, APCBEE Procedia 8, 119-124.

Widiyanti, A., Susanti, L., Sutalaksana, I. Z., Muslim, K. 2015. Ethic differences in Indonesian anthropometry data: Evidence from three different largest ethnics. International Journal of Indsustrial Ergonomics, 47, 72-78.

Wingnjosoebroto, S. 2008. Ergonomi Studi Gerak dan Waktu. Guna Widya: Surabaya.

Yap, W. S., Chan, C. C., Chan, S.P., Wang, Y.T., 2001, Ethnic Differences in Anthropometry Among Adult Singaporean Chinese, Malays and Indians, and their effects on Lung Volumes, Respir. Med., 297-304 